\title{
Antibacterial activity of Momordica charantia L. and Citrus limon L. on gram positive and gram negative bacteria
}

\author{
Zaheer Ahmed and Agha Asad Noor* \\ Institute of Microbiology, University of Sindh, Jamshoro-Pakistan \\ *Corresponding author's email: aanpathan@gmail.com \\ Citation
}

Zaheer Ahmed and Agha Asad Noor. Antibacterial activity of Momordica charantia L. and Citrus limon L. on gram positive and gram negative bacteria. Pure and Applied Biology. Vol. 9, Issue 1, pp207-218.

http://dx.doi.org/10.19045/bspab.2020.90025

\begin{tabular}{llll}
\hline \hline Received: 15/03/2019 & Revised: 04/09/2019 & Accepted: 20/09/2019 & Online First: 23/10/2019 \\
\hline \hline
\end{tabular}

\section{Abstract}

The uses of herbal medicines are well recognized since the advent of mankind having very little side effects. Their use is a cheaper and quite affordable source of antimicrobial particularly in the rural areas. Some of the microbial strains are drug resistant and are always been a threat to human life. The herbal therapy is the best choice of remedy against the drug-resistant strains, which had opened the new roads for conventional use due to several antimicrobial phytochemicals and essential oils. Momordica charantia Linnaeus $(L)$. and Citrus limon L. contain phytochemicals, which affect the bacteria, fungi, viruses, and parasites The aim of this study is to examine the effects of Momordica charantia and Citrus limon peel extracts on gram-positive and gramnegative bacteria. Preparation of extracts in ethanol, methanol, and ether were prepared and activation of test cultures, antimicrobial assay by disc diffusion, well diffusion and spectrophotometry at $600 \mathrm{~nm}$. The greater zones of inhibition were determined by ethanolic extract of Momordica charantia on the growth of Bacillus cereus and Pseudomonas aeruginosa whereas Citrus limon methanolic peel extract revealed the greater effects on Staphylococcus aureus, Streptococcus pyogenes, and Escherichia coli at 15 and $20 \mu 1$ concentrations respectively. The observations concluded that both the plant extracts have effects on bacteria that indicate that the preparations of these extracts up to pharmaceutical standard may be effectively used as antibacterial therapy against gram-positive and gram-negative bacteria.

Keywords: Citrus limon peel; G+ve and G-ve bacteria; Momordica charantia; Soxhlet extraction

\section{Introduction}

Antibiotics are being used for the remedial purpose of the infections in the prescribed doses. As long as the use of antimicrobial substances got the great significance, there were the issues of the emergence of antimicrobial resistance [1, 2]. Since a long time, before Christ, men depend upon the use of natural products, which are known the important source of medicines. The long use of herbal extracts from medicinal plants and their products played a significant role to eliminate the infectious diseases and also possessing antioxidant, anti-inflammatory and anti-cancer potentials [3-6]. The use of allopathic and herbal medicines among the older populations was more important in chronic disease. It explored the great significance for clinical applications of the effectiveness and care of herbal medicines 
alone and also with the combination of traditional drugs. World Health Organization (WHO) reported the use of medicinal plants for treatment in the form of synthetic and semisynthetic drugs. WHO also reported that $80 \%$ of the global population uses this form of medicines $[7,8]$.

Momordica charantia, (Bitter gourd) a globally used vegetable is commonly called as Karela. It is significant tonic and laxative for remedy of the disorders of the gastrointestinal tract, disorders of skin, nose and bones and liver. Its effects are also known against blood cancer, malarial infection, dysmenorrhea, renal stone and anal hemorrhoids [9]. Bitter gourd as the food was used by people of tropical areas. Besides, the use as vegetable, the Karela leaves and fruits are being used in the form of tea, soups and also beer [10]. Citrus is a significant global fruit tree crop, belongs to the Rutaceae family possessing the phenolic compounds, vitamins, minerals and also carotenoids and have antioxidant activity [11-15]. Citrus fruits possess flavonoids that are considered as a protective agent against heart diseases and cancer and Ischemic stroke. Citrus limon $L$. is significantly used in small quantities, helps give taste to salads, various drinks and desserts. The health benefits of lemon include the maintenance of hypertension, iron absorption rising immunity, providing nutritional value including calories (17), 1.45 $\mathrm{g}$ of sugar, Iron $(0.5 \mathrm{~g})$, folate $(9 \mu \mathrm{g})$, protein $(0.64 \mathrm{~g})$, fat $(0.17 \mathrm{~g})$ potassium $(116 \mathrm{mg})$, carbohydrate $(5.41 \mathrm{~g})$, calcium $(15 \mathrm{mg})$, zinc (0.05), magnesium (7 mg), phosphorus (13 $\mathrm{mg}$ ) a rich source of vitamin $\mathrm{C}$, which is required for the synthesis of collagen [16].

\section{Materials and Methods}

Preparation of crude extract in water

Crude extract of bitter gourd and lemon peels was prepared by mixing ten grams of powdered extract in $40 \mathrm{ml}$ of the warm distilled water. Each flask was allowed for 20 minutes time at $80^{\circ} \mathrm{C}$ in water bath. After mixing the test extracts were allowed to cool for $24 \mathrm{~h}$. for percolation. Later on, the extracts were passed through double layered muslin cloth and the filtrate was allowed for centrifugation for thirty minutes at $5000 \mathrm{rpm}$. These extracts were again dissolved in 100 $\mathrm{ml}$ of distilled water mixed well and filtered by $0.2 \mathrm{~mm}$ size Millipore filter [17].

Preparation of aqueous extracts in solvents

The Momordica charantia L. and Citrus limon $L$. were purchased from local market of Jamshoro. Both vegetables were washed with tap water, surface was sterilized by $70 \%$ ethanol and rinsed with sterile double distilled water [18] and later on the vegetables were dried with Whattman filter paper and kept for one hour. The vegetables were peeled and allowed for 5-7 days in shadow to dry. The peeled skin of both vegetables were ground to powder and filtered to get fine powder and kept in freezer. The powdered samples $(1 \mathrm{~g})$ were added in $100 \mathrm{ml}$ of ethanol, methanol and ether separately and extracted through the soxhlet apparatus for $24 \mathrm{~h}$. at room temperature [19, 20]. Later on the extracts were allowed at 150 $\mathrm{rpm}$ agitation in rotary incubator for $24 \mathrm{~h}$. for evaporation then filtered through Whattman No. 1 filter paper [20]. The concentrations were made by mixing respective solvents (100 ml) volume / volume in the filtered extracts.

\section{Selection of bacterial isolates}

Four different bacterial isolates; both Gram positive and Gram negative bacteria Bacillus cereus, Staphylococcus aureus (S. aureus), Streptococcus pyogenes (Str. pyogenes). Bacillus cereus (B. cereus), Pseudomonas aeruginosa (Ps. aeruginosa) and Escherichia coli (E. coli) were isolated and examined for the cultural characters, morphological characters and biochemical characters according to the methods of [18]. 


\section{Antibacterial activity of test extracts Disc diffusion method}

The antibacterial activity was performed by the method of [21]. The broth culture of the test bacteria was maintained at $10^{6}$ cells $/ \mathrm{ml}$ using hemocytometer (Quijing-China) The bacterial cultures $(100 \mu \mathrm{L})$ were separately incubated at $37^{\circ} \mathrm{C}$ for $24 \mathrm{~h}$ to observe the colonies later on a small portion of colony was emulsified in nutrient broth and kept for 30 minutes to activate the test culture. Using sterile commercial swab the activated cultures were separately inoculated on Mueller Hinton agar plates (Oxoid). Filter paper discs of $6 \mathrm{~mm}$ size were prepared, sterilized and impregnated in crude extract and each aqueous extract for 5 minutes and later dried in air for 10 minutes and placed on the surface of the inoculated nutrient agar plates. Ampicillin disc of $10 \mu \mathrm{g}$ was used a positive control and 5\% DMSO as negative control.

\section{Agar well diffusion method}

The broth culture of the test bacteria were inoculated by swab and three wells of $6 \mathrm{~mm}$ size were bores by sterile cork borer. A small volume of $(1 \mu \mathrm{l})$ of molten nutrient agar was poured in each bore of each agar plate. After solidification of nutrient agar in bored wells $0.3 \mathrm{ml}$ of aqueous extract of ethanol, methanol and ether) of bitter gourd and lemon was poured allowed the plates for few minutes at room temperature and the plates were incubated for $24 \mathrm{~h}$ at $37^{\circ} \mathrm{C}$. The diameters of antibacterial activities of water, ethanol, methanol and ether extracts were measured by zone of inhibition in $\mathrm{mm}$ [22].

\section{Spectroscopic studies}

Different volumes of aqueous extract of bitter gourd and lemon prepared in ethanol, methanol and ether were taken in 2, 10, 15, 20,25 microliter $(\mu 1)$ concentrations and mixed in $1 \mathrm{ml}$ of the culture broth of each test culture in separate flasks. This suspension was mixed gently and absorption was determined at $600 \mathrm{~nm}\left(A_{600}\right)$ by Hitachi U-1800 spectrophotometer.

\section{Results}

The effects of Ampicillin $10 \mu \mathrm{g}$ and Dimethysulfoxide (DMSO) 5\% were observed and positive and negative control respectively. The findings indicated varying zones of growth inhibition in positive control. Ampicillin showed greater effect on Pseudomonas aeruginosa strains $(22 \mathrm{~mm})$ followed by Staphylococcus aureus, Bacillus cereus whereas no zone observed by DMSO as negative control (Table 1). The test aqueous extract of Momordica charantia by disc diffusion method showed greater effect $(3 \mathrm{~mm})$ on $S$. aureus at $20 \mu \mathrm{l}$, B. cereus $15 \mu 1$ and $P$ s. aeruginosa $5 \mu \mathrm{l}$ in water (Table 2), (16 mm) on $S$. aureus at 15 $\mu 1$, followed by $(15.5 \mathrm{~mm})$ B. cereus at $15 \mu \mathrm{l}$ and $(14 \mathrm{~mm})$ Ps. aeruginosa at $20 \mu \mathrm{l}$ in ethanol (Table 3) whereas $(11 \mathrm{~mm})$ on $B$. cereus at $20 \mu \mathrm{l}$ followed by $(9 \mathrm{~mm}) \mathrm{Str}$. pyogenes at $20 \mu \mathrm{l},(8 \mathrm{~mm}) \mathrm{S}$. aureus, Ps. aeruginosa and E.coli at 15, 20, $20 \mu \mathrm{l}$ in methanol respectively (Table 4$)$ and $(8 \mathrm{~mm})$ Ps. aeruginosa at $25 \mu 1$ followed by ( $7 \mathrm{~mm}$ ) Str. pyogenes at $20, S$. aureus at 25 and (4 $\mathrm{mm}) E$. coli at $20 \mu \mathrm{l}$ in ether respectively (Table 5).

The test aqueous extract of Momordica charantia by agar well diffusion method revealed greater effect $(3 \mathrm{~mm})$ on $S$. aureus and $B$. cereus at $20 \mu \mathrm{l}$ and $25 \mu \mathrm{l}$ followed by (2.6 mm) E. coli, (1.8 mm) Ps. aeruginosa $(1.7 \mathrm{~mm})$ Str. pyogenes at 15, 20, $20 \mu \mathrm{l}$ in water respectively (Table 6), (16. mm) $S$. aureus, (16 mm) B. cereus, (13.5 mm) Str. pyogenes, (12.5 mm) Ps. aeruginosa and (10.4 mm) E. coli at 15, 15, 15, 20 and $25 \mu 1$ respectively in ethanol (Table 7) whereas $(10,8,10,8.29 .2 \mathrm{~mm})$ zone on $S$. aureus, Str. pyogenes, B. cereus, Ps. aeruginosa and E.coli at $20 \mu \mathrm{l}$ respectively in methanol (Table 8) and (9.4 mm) E. coli, (9 mm) Ps. aeruginosa, (8.2 $\mathrm{mm})$ Str. pyogenes, $(7 \mathrm{~mm})$ 
B. cereus and $(6.2 \mathrm{~mm}) \mathrm{S}$. aureus at 25,25 , 20, 20 and $25 \mu \mathrm{l}$ respectively (Table 9 ).

On the other hand the aqueous extract of Citrus limon by disc diffusion method revealed (5, 5, $5 \mathrm{~mm}) S$. aureus, Str. pyogenes, Ps. aeruginosa at 10, 20, $20 \mu \mathrm{l}$ and $(4,3 \mathrm{~mm})$ zone on B. cereus and E. coli at 20,20 $\mu 1$ respectively in water (Table 10). The greater zone on Citrus limon in ethanol extract was observed on S. aureus, Str. pyogenes, Ps. aeruginosa, B. cereus and E.coli $(16,16,15.8,15$ and $11 \mathrm{~mm})$ zone at 20, 25, 25, 25, $25 \mu 1$ respectively (Table 11) and in methanol the zone of growth inhibition of Str. pyogenes, S. aureus, E. coli, B. cereus and Ps. aeruginosa was observed $16,15.5,15.14$ and $12 \mathrm{~mm}$ at 20, 20, 20, 25 and $25 \mu 1$ respectively (Table 12) whereas test extract in ether showed 8.5, 7.6, 7.5, 7.5 and $7 \mathrm{~mm}$ zone of inhibition of Ps. aeruginosa, Str. pyogenes, B. cereus, E.coli and $S$. aureus at 25, 25, 20, 20 and $15 \mu 1$ concentration respectively (Table 13). The agar well diffusion method revealed greater

Table 1. Determination of negative (5\% DMSO) and positive control (Ampicillin $10 \mu \mathrm{g}$ ) on test bacteria

\begin{tabular}{|c|c|c|}
\hline \multirow{2}{*}{ Bacteria } & Positive control & Negative control \\
\hline & $\begin{array}{c}\text { Ampicillin }(10 \mu \mathrm{l}) \\
\text { zone size }(\mathrm{mm})\end{array}$ & $\begin{array}{c}\text { DMSO } \\
(5 \%)\end{array}$ \\
\hline Staphylococcus aureus & 20 & 00 \\
\hline Streptococcus pyogenes & 18 & 00 \\
\hline Bacillus cereus & 20 & 00 \\
\hline Pseudomonas aeruginosa & 22 & 00 \\
\hline Escherichia coli & 16 & 00 \\
\hline
\end{tabular}

Table 2. Determination of antibacterial activity of Momordica charantia in water by disc diffusion method

\begin{tabular}{|c|c|c|c|c|c|}
\hline \multirow{2}{*}{ Test bacteria } & \multicolumn{5}{|c|}{ Zone size (mm) } \\
\cline { 2 - 6 } & \multicolumn{5}{|c|}{ Concentration of extracts $(\boldsymbol{\mu l})$} \\
\cline { 2 - 6 } & $\mathbf{5}$ & $\mathbf{1 0}$ & $\mathbf{1 5}$ & $\mathbf{2 0}$ & $\mathbf{2 5}$ \\
\hline Staphylococcus aureus & 00 & 00 & 00 & 03 & $03^{ \pm 1}$ \\
\hline Streptococcus pyogenes & 00 & 00 & 02 & 02 & 02 \\
\hline Bacillus cereus & 02 & 02 & 03 & 03 & 03 \\
\hline Pseudomonas aeruginosa & 03 & $02^{ \pm 1}$ & 03 & 03 & 03 \\
\hline Escherichia coli & 00 & 00 & 00 & 00 & $02^{ \pm 1}$ \\
\hline
\end{tabular}


Table 3. Determination of antibacterial activity of Momordica charantia in ethanol by disc diffusion method

\begin{tabular}{|c|c|c|c|c|c|}
\hline \multirow{2}{*}{ Test bacteria } & \multicolumn{5}{|c|}{ Zone size (mm) } \\
\cline { 2 - 6 } & \multicolumn{5}{|c|}{ Concentration of extracts $(\boldsymbol{\mu l})$} \\
\cline { 2 - 6 } & $\mathbf{5}$ & $\mathbf{1 0}$ & $\mathbf{1 5}$ & $\mathbf{2 0}$ & $\mathbf{2 5}$ \\
\hline Staphylococcus aureus & 06 & 14 & 16 & $16^{ \pm 1}$ & 16 \\
\hline Streptococcus pyogenes & 05 & 08 & 13 & 14 & 14.5 \\
\hline Bacillus cereus & 08 & 12 & 15.5 & 15.5 & 15.5 \\
\hline Pseudomonas aeruginosa & 06 & 08 & 12 & 14 & 14 \\
\hline Escherichia coli & 04 & $04^{ \pm 1}$ & 07 & 09 & 09 \\
\hline
\end{tabular}

Table 4. Determination of antibacterial activity of Momordica charantia in methanol by disc diffusion method

\begin{tabular}{|c|c|c|c|c|c|}
\hline \multirow{2}{*}{ Test bacteria } & \multicolumn{5}{|c|}{ Zone size (mm) } \\
\cline { 2 - 6 } & \multicolumn{5}{|c|}{ Concentration of extracts $(\boldsymbol{\mu l})$} \\
\cline { 2 - 6 } & $\mathbf{5}$ & $\mathbf{1 0}$ & $\mathbf{1 5}$ & $\mathbf{2 0}$ & $\mathbf{2 5}$ \\
\hline Staphylococcus aureus & 03 & 05 & 08 & 08 & 08 \\
\hline Streptococcus pyogenes & 02 & 04 & 07 & 09 & 09 \\
\hline Bacillus cereus & 04 & 05 & 09 & 11 & 11 \\
\hline Pseudomonas aeruginosa & 02 & 04 & 07 & 08 & $08^{ \pm 1}$ \\
\hline Escherichia coli & 04 & 06 & 07 & 08 & 09 \\
\hline
\end{tabular}

Table 5. Determination of antibacterial activity of Momordica charantia in ether by disc diffusion method

\begin{tabular}{|c|c|c|c|c|c|}
\hline \multirow{2}{*}{ Test bacteria } & \multicolumn{5}{|c|}{ Zone size (mm) } \\
\cline { 2 - 6 } & \multicolumn{5}{|c|}{ Concentration of extracts $(\boldsymbol{\mu l})$} \\
\cline { 2 - 6 } & $\mathbf{5}$ & $\mathbf{1 0}$ & $\mathbf{1 5}$ & $\mathbf{2 0}$ & $\mathbf{2 5}$ \\
\hline Staphylococcus aureus & 00 & 03 & 04 & 05 & 07 \\
\hline Streptococcus pyogenes & 03 & 04 & 05 & 07 & 07 \\
\hline Bacillus cereus & 02 & 04 & 04 & 05 & 06 \\
\hline Pseudomonas aeruginosa & $04^{ \pm 1}$ & 05 & 06 & 07 & 08 \\
\hline Escherichia coli & 02 & 02 & 3.5 & 04 & 04 \\
\hline
\end{tabular}

Table 6. Determination of antibacterial activity of Momordica charantia in water by agar well diffusion method

\begin{tabular}{|c|c|c|c|c|c|}
\hline \multirow{2}{*}{ Test bacteria } & \multicolumn{5}{|c|}{ Zone size $(\mathrm{mm})$} \\
\cline { 2 - 6 } & \multicolumn{5}{|c|}{ Concentration of extracts $(\mu \mathrm{l})$} \\
\cline { 2 - 6 } & $\mathbf{5}$ & $\mathbf{1 0}$ & $\mathbf{1 5}$ & $\mathbf{2 0}$ & $\mathbf{2 5}$ \\
\hline Staphylococcus aureus & 00 & 00 & 02 & 02 & $03^{ \pm 1}$ \\
\hline Streptococcus pyogenes & 00 & 00 & 00 & 1.7 & $1.6^{ \pm 1}$ \\
\hline Bacillus cereus & 00 & 00 & 02 & 03 & 03 \\
\hline Pseudomonas aeruginosa & 00 & 01 & 01 & 1.8 & 02 \\
\hline Escherichia coli & 00 & 02 & 2.6 & 2.6 & $2.5^{ \pm 1}$ \\
\hline
\end{tabular}


Table 7. Determination of antibacterial activity of Momordica charantia in ethanol by agar well diffusion method

\begin{tabular}{|c|c|c|c|c|c|}
\hline \multirow{2}{*}{ Test bacteria } & \multicolumn{5}{|c|}{ Zone size (mm) } \\
\cline { 2 - 6 } & \multicolumn{5}{|c|}{ Concentration of extracts $(\boldsymbol{\mu l})$} \\
\cline { 2 - 6 } & $\mathbf{5}$ & $\mathbf{1 0}$ & $\mathbf{1 5}$ & $\mathbf{2 0}$ & $\mathbf{2 5}$ \\
\hline Staphylococcus aureus & 08 & 11 & 16.5 & 16.5 & 16.3 \\
\hline Streptococcus pyogenes & 07 & 10 & 13.5 & 13.2 & 13.2 \\
\hline Bacillus cereus & 09 & 11 & 16 & 16 & 16 \\
\hline Pseudomonas aeruginosa & 05 & 07 & 09 & 12.5 & 12.5 \\
\hline Escherichia coli & 04 & $04^{ \pm 1}$ & 07 & 10 & 10.4 \\
\hline
\end{tabular}

Table 8. Determination of antibacterial activity of Momordica charantia in methanol by agar well diffusion method

\begin{tabular}{|c|c|c|c|c|c|}
\hline \multirow{2}{*}{ Test bacteria } & \multicolumn{5}{|c|}{ Cone size (mm) } \\
\cline { 2 - 6 } & \multicolumn{5}{|c|}{ Concentration of extracts $(\boldsymbol{\mu l})$} \\
\cline { 2 - 6 } & $\mathbf{5}$ & $\mathbf{1 0}$ & $\mathbf{1 5}$ & $\mathbf{2 0}$ & $\mathbf{2 5}$ \\
\hline Staphylococcus aureus & 07 & 8.2 & 09 & 10 & 10 \\
\hline Streptococcus pyogenes & 04 & 5.5 & 07 & 08 & 08 \\
\hline Bacillus cereus & 6.5 & 7.2 & 09 & 10 & 10 \\
\hline Pseudomonas aeruginosa & 05 & 5.8 & 07 & 8.2 & 8.2 \\
\hline Escherichia coli & 05 & 6.4 & 7.3 & $9.2^{ \pm 1}$ & 9.2 \\
\hline
\end{tabular}

Table 9. Determination of antibacterial activity of Momordica charantia in ether by agar well diffusion method

\begin{tabular}{|c|c|c|c|c|c|}
\hline \multirow{2}{*}{ Test bacteria } & \multicolumn{5}{|c|}{ Zone size (mm) } \\
\cline { 2 - 6 } & \multicolumn{5}{|c|}{ Concentration of extracts $(\boldsymbol{\mu l})$} \\
\cline { 2 - 6 } & $\mathbf{5}$ & $\mathbf{1 0}$ & $\mathbf{1 5}$ & $\mathbf{2 0}$ & $\mathbf{2 5}$ \\
\hline Staphylococcus aureus & 00 & 02 & 05 & 5.8 & 6.2 \\
\hline Streptococcus pyogenes & 04 & 05 & 07 & 8.2 & 8.2 \\
\hline Bacillus cereus & 3.7 & 4.5 & 06 & 07 & 07 \\
\hline Pseudomonas aeruginosa & 04 & 4.8 & 06 & 07 & 09 \\
\hline Escherichia coli & 05 & 6.8 & 7.5 & 8.5 & 9.4 \\
\hline
\end{tabular}

Table 10. Determination of antibacterial activity of Citrus limon in water by disc diffusion method

\begin{tabular}{|c|c|c|c|c|c|}
\hline \multirow{2}{*}{ Test bacteria } & \multicolumn{5}{|c|}{ Cone size (mm) } \\
\cline { 2 - 6 } & \multicolumn{5}{|c|}{ Concentration of extracts $(\boldsymbol{\mu l})$} \\
\cline { 2 - 6 } & $\mathbf{5}$ & $\mathbf{1 0}$ & $\mathbf{1 5}$ & $\mathbf{2 0}$ & $\mathbf{2 5}$ \\
\hline Staphylococcus aureus & 03 & 05 & 05 & 05 & 05 \\
\hline Streptococcus pyogenes & 02 & 3.5 & 04 & 05 & $04^{ \pm 1}$ \\
\hline Bacillus cereus & 03 & 3.5 & 3.5 & 04 & 04 \\
\hline Pseudomonas aeruginosa & 01 & 02 & 03 & 05 & 05 \\
\hline Escherichia coli & 02 & 1.5 & 02 & 03 & 03 \\
\hline
\end{tabular}


Table 11. Determination of antibacterial activity of Citrus limon in ethanol by disc diffusion method

\begin{tabular}{|c|c|c|c|c|c|}
\hline \multirow{2}{*}{ Test bacteria } & \multicolumn{5}{|c|}{ Cone size (mm) } \\
\cline { 2 - 6 } & \multicolumn{5}{|c|}{ Concentration of extracts $(\boldsymbol{\mu l})$} \\
\cline { 2 - 6 } & $\mathbf{5}$ & $\mathbf{1 0}$ & $\mathbf{1 5}$ & $\mathbf{2 0}$ & $\mathbf{2 5}$ \\
\hline Staphylococcus aureus & 06 & 11 & 12 & 16 & 16 \\
\hline Streptococcus pyogenes & 07 & 10 & 12 & 14 & 16 \\
\hline Bacillus cereus & 06 & 11 & 12 & 13.5 & 15 \\
\hline Pseudomonas aeruginosa & 04 & 06 & 13.5 & 15 & 15.8 \\
\hline Escherichia coli & 05 & 07 & 08 & 9.5 & 11.2 \\
\hline
\end{tabular}

Table 12. Determination of antibacterial activity of Citrus limon in methanol by disc diffusion method

\begin{tabular}{|c|c|c|c|c|c|}
\hline \multirow{2}{*}{ Test bacteria } & \multicolumn{5}{|c|}{ Zone size (mm) } \\
\cline { 2 - 6 } & \multicolumn{5}{|c|}{ Concentration of extracts $(\boldsymbol{\mu l})$} \\
\cline { 2 - 6 } & $\mathbf{5}$ & $\mathbf{1 0}$ & $\mathbf{1 5}$ & $\mathbf{2 0}$ & $\mathbf{2 5}$ \\
\hline Staphylococcus aureus & 09 & 11.4 & 13.5 & 15.5 & 15.5 \\
\hline Streptococcus pyogenes & 08 & 12.5 & 14.3 & 16 & 16 \\
\hline Bacillus cereus & 5.5 & 07 & 8.6 & 11 & 14 \\
\hline Pseudomonas aeruginosa & 05 & 06 & 08 & 9.5 & 12 \\
\hline Escherichia coli & 08 & 10 & 12 & 15 & 15 \\
\hline
\end{tabular}

Table 13. Determination of antibacterial activity of Citrus limon in ether by disc diffusion method

\begin{tabular}{|c|c|c|c|c|c|}
\hline \multirow{2}{*}{ Test bacteria } & \multicolumn{5}{|c|}{ Cone size (mm) } \\
\cline { 2 - 6 } & \multicolumn{5}{|c|}{ Concentration of extracts $(\boldsymbol{\mu l})$} \\
\cline { 2 - 6 } & $\mathbf{5}$ & $\mathbf{1 0}$ & $\mathbf{1 5}$ & $\mathbf{2 0}$ & $\mathbf{2 5}$ \\
\hline Staphylococcus aureus & 05 & 05 & 07 & 07 & 07 \\
\hline Streptococcus pyogenes & 5.8 & 6.5 & 07 & 6.7 & 7.6 \\
\hline Bacillus cereus & 04 & 06 & 6.8 & 7.5 & 7.5 \\
\hline Pseudomonas aeruginosa & 05 & 5.8 & 07 & 08 & 8.5 \\
\hline Escherichia coli & 03 & 05 & 6.8 & 7.5 & 7.5 \\
\hline
\end{tabular}

Table 14. Determination of antibacterial activity of Citrus limon in water by agar well diffusion method

\begin{tabular}{|c|c|c|c|c|c|}
\hline \multirow{2}{*}{ Test bacteria } & \multicolumn{5}{|c|}{ Zone size $(\mathbf{m m})$} \\
\cline { 2 - 6 } & \multicolumn{5}{|c|}{ Concentration of extracts $(\boldsymbol{\mu l})$} \\
\cline { 2 - 6 } & $\mathbf{5}$ & $\mathbf{1 0}$ & $\mathbf{1 5}$ & $\mathbf{2 0}$ & $\mathbf{2 5}$ \\
\hline Staphylococcus aureus & 2.5 & 4.8 & 5.2 & 06 & 06 \\
\hline Streptococcus pyogenes & 03 & 3.5 & 4.3 & 5.5 & 6.2 \\
\hline Bacillus cereus & 03 & 3.5 & 04 & 04 & 04 \\
\hline Pseudomonas aeruginosa & 02 & 03 & 3.8 & 05 & 5.7 \\
\hline Escherichia coli & 02 & 02 & 3.4 & 4.5 & 4.5 \\
\hline
\end{tabular}


Table 15. Determination of antibacterial activity of Citrus limon in ethanol by agar well diffusion method

\begin{tabular}{|c|c|c|c|c|c|}
\hline \multirow{2}{*}{ Test bacteria } & \multicolumn{5}{|c|}{ Zone size (mm) } \\
\cline { 2 - 6 } & \multicolumn{5}{|c|}{ Concentration of extracts $(\boldsymbol{\mu l})$} \\
\cline { 2 - 6 } & $\mathbf{5}$ & $\mathbf{1 0}$ & $\mathbf{1 5}$ & $\mathbf{2 0}$ & $\mathbf{2 5}$ \\
\hline Staphylococcus aureus & 06 & 10.8 & 12 & 14.2 & 14.2 \\
\hline Streptococcus pyogenes & 05 & 7.5 & 11 & 12.5 & 12.5 \\
\hline Bacillus cereus & 5.4 & 08 & 12.5 & 15 & 15 \\
\hline Pseudomonas aeruginosa & 6.5 & 08 & 13.7 & 15 & 15 \\
\hline Escherichia coli & 06 & 09 & 13 & 14.2 & $14.3^{ \pm 1}$ \\
\hline
\end{tabular}

Table 16. Determination of antibacterial activity of Citrus limon in methanol by agar well diffusion method

\begin{tabular}{|c|c|c|c|c|c|}
\hline \multirow{2}{*}{ Test bacteria } & \multicolumn{5}{|c|}{ Zone size (mm) } \\
\cline { 2 - 6 } & \multicolumn{5}{|c|}{ Concentration of extracts $(\boldsymbol{\mu l})$} \\
\cline { 2 - 6 } & $\mathbf{5}$ & $\mathbf{1 0}$ & $\mathbf{1 5}$ & $\mathbf{2 0}$ & $\mathbf{2 5}$ \\
\hline Staphylococcus aureus & 05 & 8.7 & 13 & 17.8 & 17.8 \\
\hline Streptococcus pyogenes & 7.5 & 12 & 14 & 16.5 & 16.5 \\
\hline Bacillus cereus & 5.5 & 07 & 08 & 10 & 10 \\
\hline Pseudomonas aeruginosa & 06 & 7.5 & 8.5 & 11.4 & 11.4 \\
\hline Escherichia coli & 08 & 10 & 13 & $17.4^{ \pm 1}$ & 17.5 \\
\hline
\end{tabular}

Table 17. Determination of antibacterial activity of Citrus limon in ether by agar well diffusion method

\begin{tabular}{|c|c|c|c|c|c|}
\hline \multirow{2}{*}{ Test bacteria } & \multicolumn{5}{|c|}{ Zone size (mm) } \\
\cline { 2 - 6 } & \multicolumn{5}{|c|}{ Concentration of extracts $(\boldsymbol{\mu l})$} \\
\cline { 2 - 6 } & $\mathbf{5}$ & $\mathbf{1 0}$ & $\mathbf{1 5}$ & $\mathbf{2 0}$ & $\mathbf{2 5}$ \\
\hline Staphylococcus aureus & 02 & 03 & 03 & 3.5 & 05 \\
\hline Streptococcus pyogenes & 04 & 05 & 5.5 & 07 & 07 \\
\hline Bacillus cereus & 4.5 & 05 & 6.4 & 7.5 & 08 \\
\hline Pseudomonas aeruginosa & 03 & 3.7 & 05 & 7.5 & 7.5 \\
\hline Escherichia coli & 04 & 05 & 6.5 & 7.2 & 08 \\
\hline
\end{tabular}




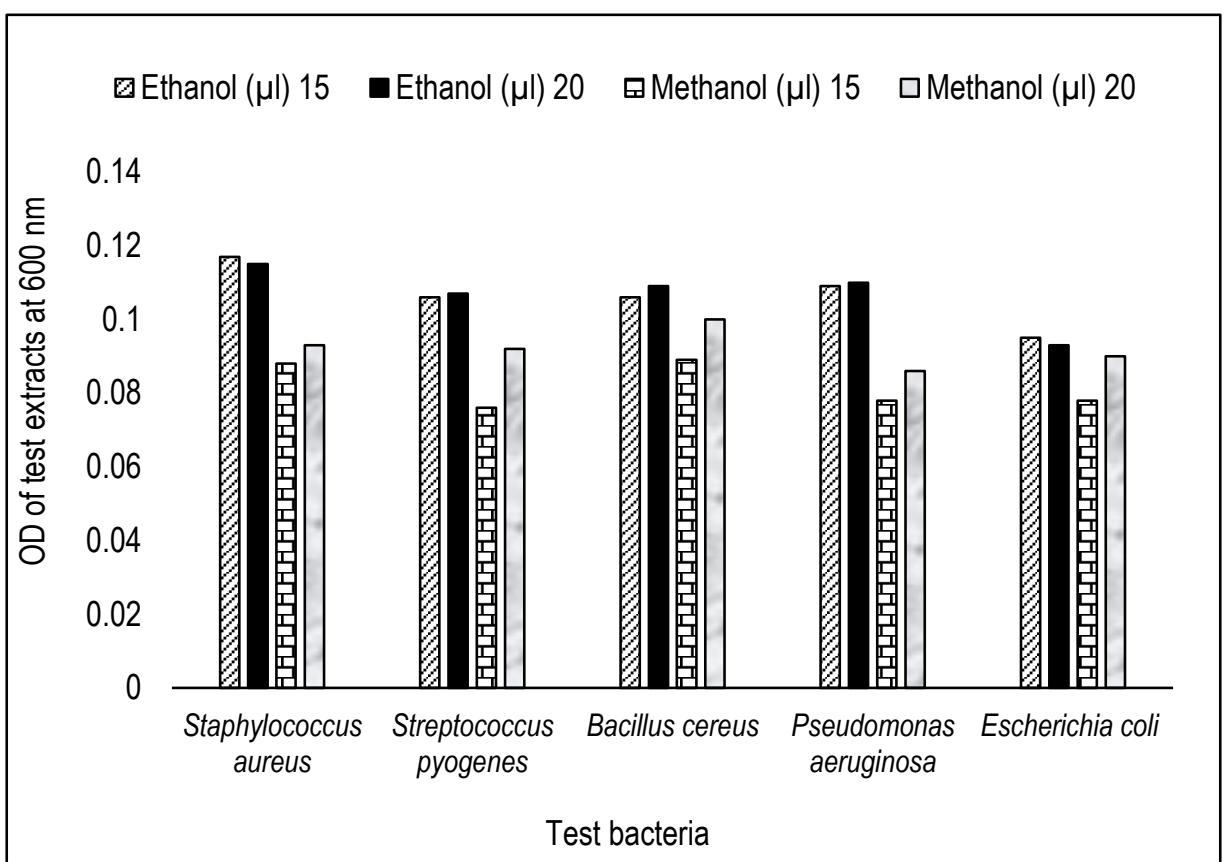

Figure 1. Spectroscopic studies of Momordica charantia extract in ethanol and methanol at 15 and $20 \mu l$ concentration at $600 \mathrm{~nm}$

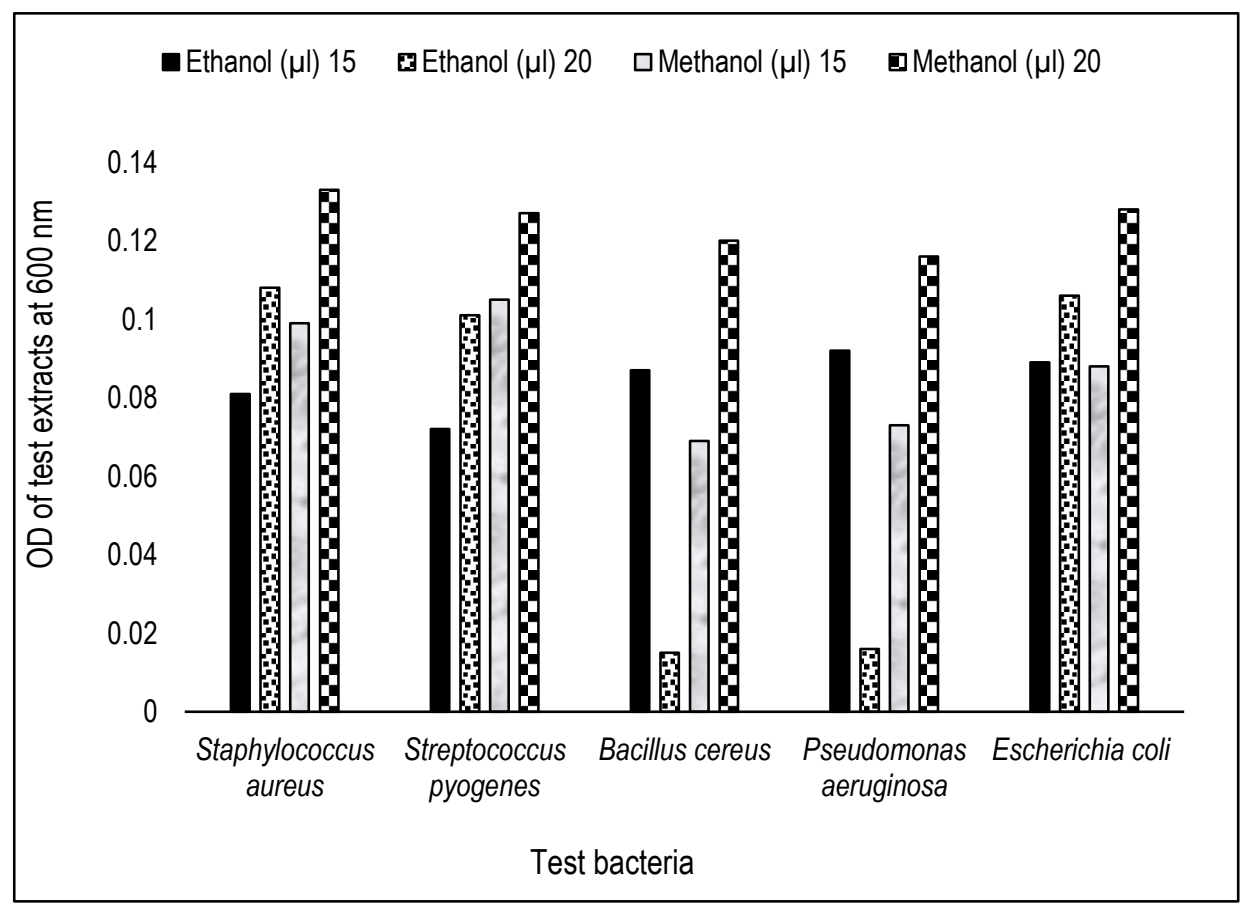

Figure 2. Spectroscopic studies of Citrus limon extract in ethanol and methanol at 15 and $20 \mu$ l concentration at $600 \mathrm{~nm}$. 


\section{Discussion}

All test strains were examined for their sensitivity against the positive control (Ampicillin) and negative control (5\% DMSO) that revealed sensitivity of ally test strains to ampicillin antibiotic with varying zone sizes whereas DMSO showed no effect on all test strains (Table 1). Bitter gourd peels when dissolved in water revealed insignificant effect on test strains not more than 4-5 $\mathrm{mm}$ zone of inhibition by disc diffusion method and agar well diffusion methods (Table 2,6) whereas in extract in ethanol showed antibacterial effects on test bacteria at varying concentrations. The greater effects were observed on $S$. aureus and $B$. cereus at $15 \mu 1$ concentration by disc diffusion and agar well diffusion methods (Table 3, 7).

The lemon peel extract in methanol showed the significant effects on a test bacteria. The greater effect of lemon extract in methanol was observed on Staphylococcus aureus, E.coli, Streptococcus pneumoniae and Pseudomonas aeruginosa respectively by agar well diffusion method. The agar well diffusion method showed the greater zones as compared to the disc diffusion method due to the percolation of the aqueous extracts more rapidly in the agar medium. The spectroscopy of two concentration (15, $20 \mu \mathrm{l})$ of extracts in ethanol and methanol of Momordica charantia and Citrus limon was done to compare the greater optical density of test bacteria at $A_{600}$.

The aqueous extracts of bitter gourd in water, methanolic and ether revealed the lesser effects on the test bacteria compared to the ethanolic extracts, which has considerable bacteriostatic or bactericidal may be due to higher concentration of dissolved antimicrobial compounds and their polarity including the momordin, alpha- and beta-momorcharin, cucurbitac in B1 and oleanolic acid. On the other side, the limonene as major constituent in lemon also inhibit bacterial growth. The reason of variable antibacterial effects of ethanolic and methanolic extracts on bacteria are due to their cell wall composition including the peptidoglycan and phospholipid layer in Gram positive and Gram negative bacteria respectively. The antibacterial effect may be due to lipid bilayer, where the extract penetrates and disintegrates the membranous structure of bacteria [23-27]. Our findings at $A_{600}$ essentially confers the effects of Momordica charantia and Citrus limon at $15,20 \mu \mathrm{l}$ concentrations on test bacteria.

\section{Conclusion}

It is concluded that the test extracts prtepared in ethanol and methanol are more effective than the extracts in water and ether on the test bacteria. Bitter gourd extract showed higher antibacterial activity against Gram negative bacteria Staphylococcus aureus and Bacillus cereus at $15 \mu 1$ concentration. The lemon peel extract in methanol showed the greater effects on Staphylococcus aureus, E.coli, Streptococcus pneumoniae and Pseudomonas aeruginosa respectively $20 \mu 1$ concentration. It is also concluded that the agar well diffusion method is more reliable method than the disc diffusion method. The spectroscopic studies confers the effects of Momordica charantia and Citrus limon at $15,20 \mu \mathrm{l}$ respectively.

\section{Authors' contributions}

Conceived and designed the experiments: AA Noor \& $Z$ Ahmed, Performed the experiments: Z Ahmed, Analyzed the data: AA Noor, Contributed materials/ analysis/ tools: Z Ahmed \& AA Noor, Microbiology Research Laboratory, Institute of Microbiology, Wrote the paper: Z Ahmed.

\section{References}

1. Kumar S \& Singh BR (2013). An Overview of Mechanisms and Emergence of Antimicrobials Drug Resistance. Adv Ani and Vet Sci 1: 7-14. 
2. Canton R \& Mar'1a-Isabel M (2011). Emergence and spread of antibiotic resistance following exposure to antibiotics. FEMS Microbiol Rev 35: 977-991.

3. Siddiqui AA, Iram F, Siddiqui $\mathrm{S} \& \mathrm{Sahu}$ K (2014). Role of Natural Products in Drug Discovery Process. Int J Drug Dev \& Res 6(2): 172-204.

4. Dias DA, Urban S, \& Roessner U (2012). A Historical Overview of Natural Products in Drug Discovery. Review. Metabolites 2: 303-336.

5. Joseph B \& Jini D (2013). Antidiabetic effects of Momordica charantia (bitter melon) and its medicinal potency. Asian Pac J Trop Dis 3: 93-102.

6. Majekodunmi SO (2015). Review of extraction of medicinal plants for pharmaceutical research. J Medi Medical 3: 521-527.

7. Rivera JO, Loya AM, \& Ceballos R (2013). Use of Herbal Medicines and Implications for Conventional Drug Therapy Medical Sciences. Altern. Integ. Med. 2: 130.

8. Ali J, Das B \& Saikia T (2017). Antimicrobial activity of lemon peel (Citrus limon) extract. Int $J$ of Current Pharmaceutical Res 9: 79-82.

9. Kumar DS, Sharathnath KV, Yogeswaran P, Harani A, Sudhakar K, Sudha P, \& Banji D (2010). A medicinal potency of Momordica charantia. Int J Pharma Sci Rev and Res 1: 95-100.

10. Kumar KPS \& Bhowmik D (2010). Traditional medicinal uses and therapeutic benefits of Momordica charantia L. Int J Pharma Sci Rev and Res 4: 23-28.

11. González-Molina E, Domínguez-Perles $\mathrm{R}$, Moreno DA \& García-Viguera C (2010). Natural bioactive compounds of Citrus limon for food and health. $J$ Pharma. and Biomedical Analysis 51: 327-345.
12. https://en.wikipedia.org/wiki/Lemon / Accessed on 06.01.2019.

13. Proteggente AR, Pannala AS, Paganga $\mathrm{G}$, Van Buren LE, Wagner S, Wise-man F, Van De Put C, Dacombe CA, \& RiceEvans (2002). The antioxidant activity of regularly consumed fruit and vegetables reflects their phenolic and vitamin $\mathrm{c}$ composition. Free Radical Res 36: 217233.

14. Vinson JA, Proch J \& Bose P (2001). Determination of quantity and quality of polyphenol antioxidants in foods and beverages. Methods Enzymol 335: 103114.

15. Wilmsen PK, Spada DS \& Salvador M (2005). Antioxidant Activity of the Flavonoid Hesperidin in Chemical and Biological Systems. J Agric Food Chem 53: 4757-4761.

16. https://www.medicalnewstoday.com

17. Gupta M, Sharma S \& Bhadauria R (2016). In vitro efficacy of Momordica charantia extracts against phytopathogenic fungi, Fusarium oxysporum. J Biopest 9: 8-22.

18. Hindi NKK, \& Chabuck ZAG. (2013). Antimicrobial Activity of Different Aqueous Lemon Extracts. $J$ Appl Pharma Sci 3: 74-78.

19. Ozusaglam MA, \& Karakoca K (2013). Antimicrobial and antioxidant activities of Momordica charantia from Turkey. Afr J Biotechnol 12: 1548-1558.

20. Tan SP, Parks SE, Stathopoulos CE, \& Roach DR (2014). Extraction of Flavonoids from Bitter Melon. Food and Nut Sci 5: 458-465.

21. Yeo YL, Chia YY, Lee CH, Sow HS, \& Yap WS (2014). Effectiveness of Maceration Periods with Different Extraction Solvents on in-vitro Antimicrobial Activity from Fruit of Momordica charantia L. J Appl Pharma Sci 4: 16-23. 
22. Sen A, \& Amla B (2012). Evaluation of antimicrobial activity of different solvent extracts of medicinal plant: Melia Azedarach L. Int J Curr Pharma Res 4: 67-73.

23. Mwambete KD (2009). The in vitro antimicrobial activity of fruit and leaf crude extracts of Momordica charantia: A Tanzania medicinal plant. Afr Health Sci 9: 34-39.

24. Ghosh D (2014). Does Bitter Melon (Momordica charantia) have Antibacterial Property. $J$ Food Pro Technol 5: 2-5.

25. Öntaş C, Baba E, Kaplaner E, Küçükaydin S, Öztürk M \& Ercan MD (2016). Antibacterial activity of Citrus limon peel essential oil and Argania spinosa oil against fish pathogenic bacteria. Kafkas Univ Vet Fak Derg 22: 741-749.

26. Hassan IM, Ibrahim HM, Abdel Fattah A, Fattah A \& Hamed AAM (2017). Citrus sinensis and Citrus aurantiifolia Peel Extracts: Antibacterial, Antioxidant Activity and Total phenolic. Int J Curr Microbiol App Sci 6: 3983-3998.

27. Costa1 JGM, Nascimento EMM, Campos AR \& Rodrigues FFG (2011). Antibacterial activity of Momordica charantia (Curcubitaceae) extracts and fractions. José $J$ Basic and Clin Pharmacy 2: 45-51. 